\title{
The comparisons of computational models of pavement due to the dynamic load act
}

\author{
Veronika Valašková ${ }^{1, *}$ \\ ${ }^{1}$ University of Žilina, Faculty of Civil Engineering, Univerzitná 8215/1, 01026 Žilina, Slovakia
}

\begin{abstract}
Finite element method (FEM) is frequently used to solve current problems of the structural mechanics in engineering practice. The dynamic interaction of the two systems is one of the topics that can be solved using FEM. To simplify the solution of the interaction, it is possible to divide the system in two independent subsystems, vehicle and pavement. Computing software ADINA, based on the principles of the finite element modelling, was adopted to solve the given problem. The results from the first computational model can be used as the inputs for the second model. To analyse stress state of the pavement with different composition, three specific types of pavements were selected - concrete pavement, semi-rigid pavement and flexible pavement. The pavements represent the typical pavement types used for the regular road structures. This article is focused on the analysis of the stress state and the displacements of the pavement induced by the moving load from the traffic.
\end{abstract}

\section{Introduction}

Pavements are structures that are exposed to direct dynamic effects of the moving load. Unevenness of the pavement surface is the main source of the kinematic excitation for the vehicle. One of the most important kinematic excitation for the vehicle is also road obstacle. The obstacle has significant influence on the magnitude of the contact forces between the pavement surface and the vehicle tires. The actual load amplitude is variable of the time and the frequency domain. There are two basic approaches to obtain the required data - computational or experimental methods $[1,2]$.

There are many possibilities how to create the computational model of the pavement and the vehicle. 2D half-part model of the Tatra 815 vehicle and the ground represented by 3 types of the pavements with different composition were created. Results of the stressstrain analysis of the numerical models are presented in this paper. The first step of the numerical simulation involves the determination of the contact forces caused by the moving vehicle passing the obstacle. The results from the first step are used as the input for the second calculation step, evaluation of stresses in the pavement. Three models of the pavements were prepared, one for each pavement type. Pavement types were selected for typical road pavements - a concrete pavement, a semi-rigid pavement and a flexible pavement.

\footnotetext{
*Corresponding author: veronika.valaskova@,fstav.uniza.sk
} 
The theoretical solution is based on the Finite Element Method (FEM), which is adopted in numerous calculation softwares.

\section{Dynamic subsystem vehicle}

One of the most important parts of numerical simulation is the selection of the appropriate model of the vehicle. The corresponding computational model represents the implementation of the theoretical mathematical formulations. Simplification of the studied vehicle to the half-part model is often used in $2 \mathrm{D}$ analyses. The vehicle model is the combination of the mass, spring and the beam elements. The discrete model of the vehicle with finite degrees of freedom simplifies the solution from the mathematical point of view. This assumption converts partial differential equations to the ordinary differential equations. The half-part model of the Tatra 815 lorry was used for the simulations presented in this article (Fig. 1).

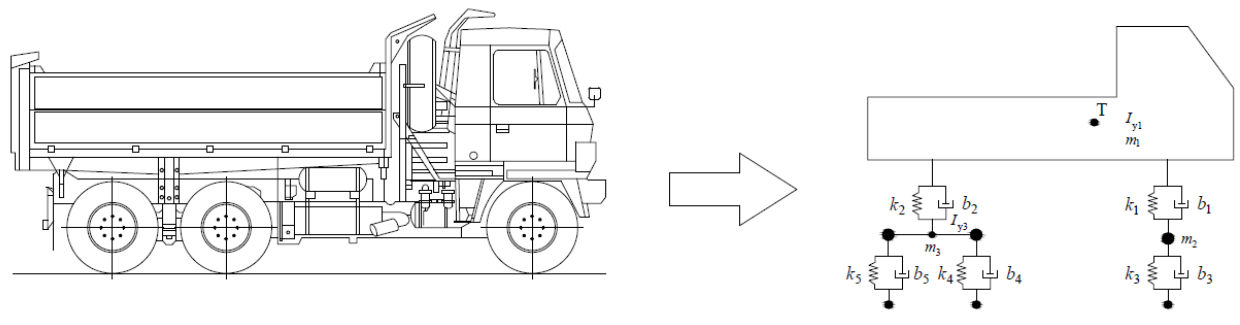

Fig. 1. Half-part model of the Tatra 815 lorry.

The half-part model of the lorry is defined by three diagonal matrices. They are mass $\mathbf{m}$, stiffness $\mathbf{k}$ and damping $\mathbf{b}$ matrices, which contain experimentally measured values [2].

$$
\begin{aligned}
\mathbf{m} & =\left\{m_{1}, I y_{1}, m_{2}, m_{3}, I y_{3}\right\} \mathbf{D}=\{11475 ; 31149 ; 455 ; 1070 ; 466\} \mathbf{D} \quad\left[\mathrm{kg}, \mathrm{kg} \cdot \mathrm{m}^{2}\right] \\
\mathbf{k} & =\left\{k_{1}, k_{2}, k_{3}, k_{4}, k_{5}\right\}_{\mathbf{D}}=\{143716.5 ; 761256 ; 1275300 ; 2511360 ; 2511360\}_{\mathbf{D}} \quad\left[\mathrm{N} \cdot \mathrm{m}^{-1}\right] \\
\mathbf{b} & =\left\{b_{1}, b_{2}, b_{3}, b_{4}, b_{5}\right\}_{\mathbf{D}}=\{19228,260197,2746,5494,5494\} \mathbf{D} \quad\left[\mathrm{kg} \cdot \mathrm{s}^{-1}\right]
\end{aligned}
$$

Natural frequencies determined as a result of the experiment measurements are consistent with the calculated natural frequencies.

$\mathbf{f}=\left\{f_{(1)} ; f_{(2)} ; f_{(3)} ; f_{(4)} ; f_{(5)}\right\}=\{1.13 ; 1.45 ; 8.89 ; 10.91 ; 11.71\} \quad[\mathrm{Hz}]$

\section{Dynamic subsystem pavement}

Three different types of road pavements were used for the analyses - the concrete pavement, the semi-rigid pavement and the flexible pavement. Material properties of the particular construction layers have been determined in accordance with the road pavement catalogues. Axisymmetric numerical model of the pavement to simulate three-dimensional stress state in the pavement structure was adopted. Each layer was modelled separately with consideration of the contact using the interface element. 


\subsection{Composition of the pavement layers}

Material characteristics of the particular pavement layers are in Tables 1 to 3. Since the dynamic loads inflict very small deformations to the ground, it is necessary to use "dynamic" values of modulus of elasticity $E$. The "dynamic" values are then higher than the "static" values.

Table 1. Composition of the layers for the concrete pavement.

\begin{tabular}{|c|l|c|c|c|c|}
\hline $\begin{array}{c}\text { Number } \\
\text { of layer }\end{array}$ & \multicolumn{1}{|c|}{ Material } & $\begin{array}{c}\text { Designation of } \\
\text { the material }\end{array}$ & $\begin{array}{c}\text { Thickness } \\
(\mathrm{mm})\end{array}$ & $\begin{array}{c}\text { Modulus of } \\
\text { elasticity } E \\
(\mathrm{MPa})\end{array}$ & $\begin{array}{c}\text { Poisson's } \\
\text { ratio }\end{array}$ \\
\hline 1 & Cement- concrete & CC & 260 & 35000 & 0.2 \\
\hline 2 & $\begin{array}{l}\text { Cement bound } \\
\text { granular mixture }\end{array}$ & CBGM & 310 & 4500 & 0.22 \\
\hline 3 & $\begin{array}{l}\text { Hydraulic road } \\
\text { binder bound } \\
\text { granular mixture }\end{array}$ & HBBM & 150 & 2000 & 0.25 \\
\hline 4 & Subgrade & S & $\infty$ & 80 & 0.35 \\
\hline
\end{tabular}

Table 2. Composition of the layers for the semi-rigid pavement.

\begin{tabular}{|c|l|c|c|c|c|}
\hline $\begin{array}{c}\text { Number } \\
\text { of layer }\end{array}$ & \multicolumn{1}{|c|}{ Material } & $\begin{array}{c}\text { Designation of } \\
\text { the material }\end{array}$ & $\begin{array}{c}\text { Thickness } \\
(\mathrm{mm})\end{array}$ & $\begin{array}{c}\text { Modulus of } \\
\text { elasticity } E \\
(\mathrm{MPa})\end{array}$ & $\begin{array}{c}\text { Poisson's } \\
\text { ratio }\end{array}$ \\
\hline 1 & Stone mastix asphalt & SMA 11 & 40 & 5500 & 0.33 \\
\hline 2 & Asphalt concrete & AC 22 & 50 & 6000 & 0.3 \\
\hline 3 & Asphalt concrete - L & AC 22-L & 50 & 3050 & 0.33 \\
\hline 4 & $\begin{array}{l}\text { Cement bound } \\
\text { granular mixtures }\end{array}$ & CBGM C3/4 & 150 & 2000 & 0.22 \\
\hline 5 & Graded aggregate & GA & 150 & 400 & 0.3 \\
\hline 6 & Subgrade & S & $\infty$ & 60 & 0.35 \\
\hline
\end{tabular}

Table 3. Composition of the layers of the flexible pavement.

\begin{tabular}{|c|l|c|c|c|c|}
\hline $\begin{array}{c}\text { Number } \\
\text { of layer }\end{array}$ & \multicolumn{1}{|c|}{ Material } & $\begin{array}{c}\text { Designation of } \\
\text { the material }\end{array}$ & Thickness & $\begin{array}{c}\text { Modulus of } \\
\text { elasticity } E \\
(\mathrm{~mm})\end{array}$ & $\begin{array}{c}\text { Poisson's } \\
\text { ratio }\end{array}$ \\
\hline 1 & Stone mastix asphalt & SMA 11 & 40 & 5500 & 0.33 \\
\hline 2 & Asphalt concrete & AC 22 & 80 & 6000 & 0.3 \\
\hline 3 & Asphalt concrete - L & AC 22-L & 100 & 3000 & 0.33 \\
\hline 4 & Unbound mixture & UM & 300 & 600 & 0.25 \\
\hline 5 & Crushed gravel & CG & 200 & 350 & 0.3 \\
\hline 6 & Subgrade & S & $\infty$ & 90 & 0.35 \\
\hline
\end{tabular}




\section{Model description}

\subsection{Model of vehicle passing over obstacle}

The numerical model of the vehicle passing over the obstacle on the pavement was compiled in ADINA FEM computational software. The pavement and the obstacle are modelled as rigid surfaces consisting of the beam elements. The obstacle is defined as a part of the pavement surface. The pavement consists of the part for acceleration (length 15 $\mathrm{m}$ ), the obstacle (length $0.94 \mathrm{~m}$ ) and the part for deceleration (length $15 \mathrm{~m}$ ). The shape of the obstacle is similar to the shapes that are recommended for the dynamic tests of the bridges. This shape is also identical with retarders on the pavement [3].

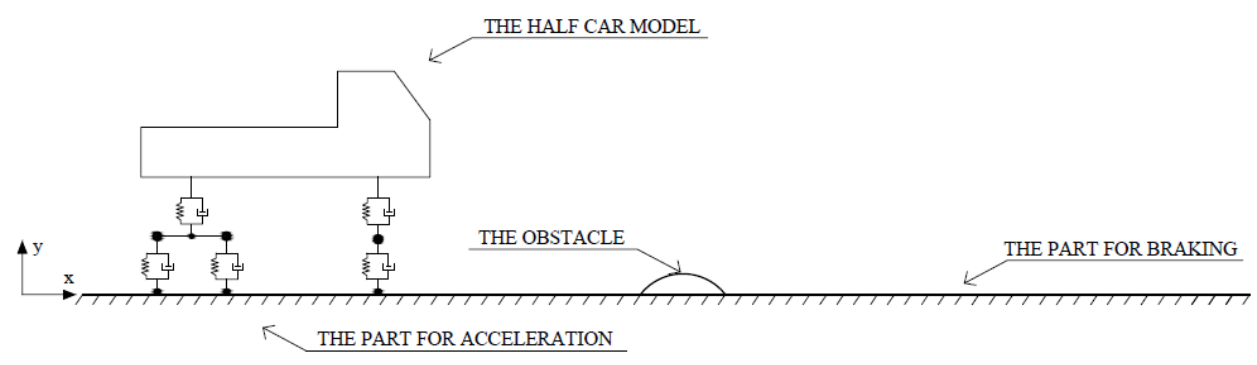

Fig. 2. The numerical model of the vehicle with the obstacle.

The obstacle was modelled as function $h(\mathrm{x})$, where $h_{0}=0.06 \mathrm{~m}$ and $2 l_{0}=0.94 \mathrm{~m}$ (Fig. 3).

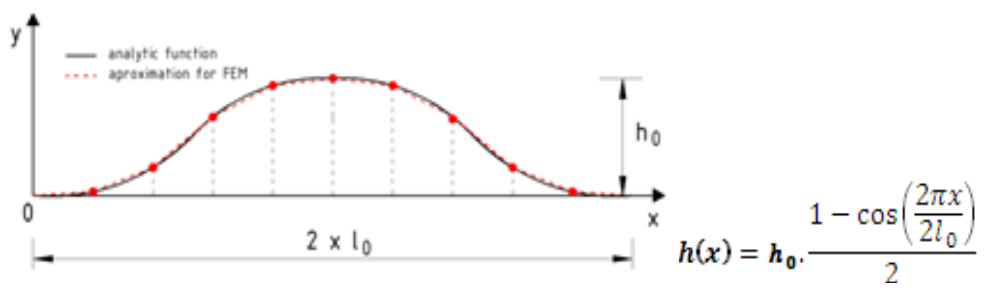

Fig. 3. The shape of the obstacle.

The vehicle passes over the obstacle at the constant velocity of $40 \mathrm{~km} / \mathrm{h}$ for all simulations. The basic time step for the simulation was selected $1 / 20 \mathrm{~s}$. The time step when the vehicle passes the obstacle was then changed to $1 / 100 \mathrm{~s}$ to obtain more accurate results. Calculated force for front tire reached $83200 \mathrm{~N}$. The contact force was then distributed over idealized squared tire contact area $250 \times 250 \mathrm{~mm}$. The tire pressure was applied as a uniform load in the second step analysis with intensity $1020408 \mathrm{~Pa}$. The load was then applied on the road pavement surface to investigate the stress-strain state of the ground.

\subsection{Pavement models}

The representative distributing area for loading was selected for a 2D numerical model. The selection of the distribute area was based on the experimental measurements. The length of the tire load is $250 \mathrm{~mm}$. The whole model was modelled in ADINA software as an axisymmetric computational model. The distribute area was then modelled with length 125 $\mathrm{mm}$. The scheme of the numerical model is shown in Fig. 4. 


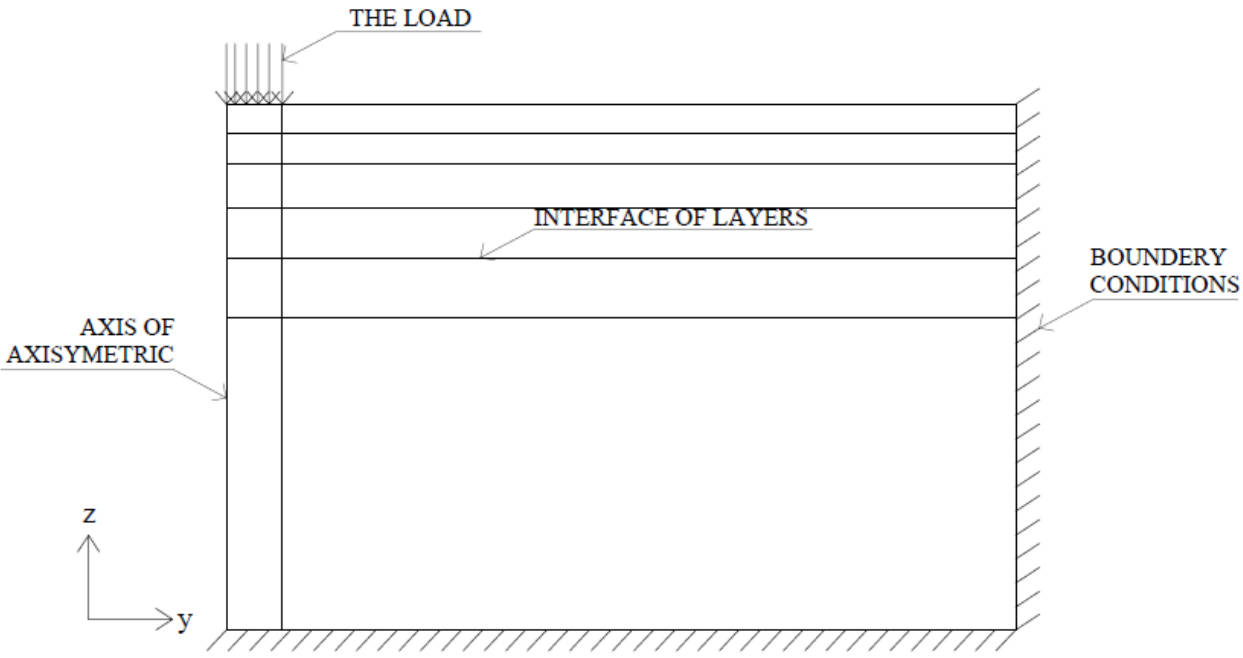

Fig. 4. Scheme of the numerical model of the pavement.

\section{Description of numerical solver}

ADINA is a commercial engineering simulation software, which is used in industry and academia to solve structural, fluid and heat transfer, and electromagnetic problems. The ADINA software can also be used to solve multiphysics problems, including fluid-structure interactions and thermo-mechanical problems.

ADINA is the acronym for Automatic Dynamic Incremental Nonlinear Analysis. The program consists of four core moduli:

- ADINA Structures for linear and nonlinear analysis of solids and structures,

- ADINA Thermal for analysis of heat transfer in solids and field problems,

- ADINA CFD for analysis of compressible and incompressible flows,

- ADINA EM for analysis of electromagnetic phenomena.

These moduli can be used fully coupled together to solve multiphysics problems where the response of the system is affected by the interaction of several distinct physical fields (e.g. fluid-structure interaction, thermo-mechanical analysis, piezoelectric coupling, Joule heating, fluid flow-mass transfer coupling, electromagnetic forces on fluids and structures, etc.) [4].

An effective implicit time integration scheme was proposed for the finite element solution of nonlinear dynamics problems. Numerical time integration is widely used in the finite element solutions of transient wave propagation problems. However, accurate solutions are difficult to obtain because of numerical dispersion and dissipation, resulting from period elongations and amplitude decays. In the solution of transient wave propagations, the errors from the spatial and temporal discretization appear together and affect each other. Analyses of these errors have led to the use of linear combinations of consistent and lumped mass matrices. Another approach is to reduce the solution errors by evaluating the mass and stiffness matrices using modified spatial integration rules. Such schemes can improve the accuracy of solutions of multi-dimensional wave propagation problems when using certain elements and meshes.

The dispersion errors resulting from the spatial discretization coupled with the temporal discretization can be analysed. The Bathe method and the Newmark trapezoidal rule are 
considered. For this purpose, it is analysed the solution obtained for the scalar wave governed by:

$$
\frac{\partial^{2} u}{\partial t^{2}}-c_{0}^{2} \nabla^{2} u=0
$$

where $u$ is the field variable and $c_{0}$ is the wave velocity. Here, body forces are not considered since we focus on the dispersion associated with the propagations of disturbances due to initial conditions. The associated finite element discretization gives:

$$
\mathbf{M} \ddot{\mathbf{U}}+c_{0}^{2} \mathbf{K U}=\mathbf{0}
$$

where $\mathbf{K}$ and $\mathbf{M}$ are the stiffness and mass matrices, and for element $(m)$ with volume $V^{(m)}$

$$
\begin{gathered}
\mathbf{M}^{(m)}=\int_{V^{(m)}} \mathbf{H}^{(m)^{T}} \mathrm{~d} V^{(m)} \\
\mathbf{K}^{(m)}=\int_{V^{(m)}}\left(\nabla \mathbf{H}^{(m)}\right)^{T}\left(\nabla \mathbf{H}^{(m)}\right) \mathrm{d} V^{(m)}
\end{gathered}
$$

Here, $\mathbf{H}^{(m)}$ and $\mathbf{U}$ are the element interpolation matrix and the nodal values of the solution, respectively. Matrices $\mathbf{M}$ and $\mathbf{K}$ in Eq. (3) are obtained by the usual summation process. In the Bathe method, the following relations are employed:

$$
\begin{gathered}
{ }^{t+\Delta t / 2} \dot{\mathbf{U}}={ }^{t} \dot{\mathbf{U}}+\left[\frac{\Delta t}{4}\right]\left({ }^{t} \ddot{\mathbf{U}}+{ }^{t+\Delta t / 2} \ddot{\mathbf{U}}\right) \\
{ }^{t+\Delta t / 2} \mathbf{U}={ }^{t} \mathbf{U}+\left[\frac{\Delta t}{4}\right]\left({ }^{t} \dot{\mathbf{U}}+{ }^{t+\Delta t / 2} \dot{\mathbf{U}}\right) \\
{ }^{t+\Delta t} \dot{\mathbf{U}}=\frac{1}{\Delta t}{ }^{t} \mathbf{U}-\left[\frac{4}{\Delta t}\right]{ }^{t+\Delta t / 2} \mathbf{U}+\frac{3}{\Delta t}{ }^{t+\Delta t} \mathbf{U} \\
{ }^{t+\Delta t} \ddot{\mathbf{U}}=\frac{1}{\Delta t}{ }^{t} \dot{\mathbf{U}}-\left[\frac{4}{\Delta t}\right]{ }^{t+\Delta t / 2} \dot{\mathbf{U}}+\frac{3}{\Delta t}{ }^{t+\Delta t} \dot{\mathbf{U}}
\end{gathered}
$$

Using Eq. (3) at times $t, t+\Delta t / 2$ and $t+\Delta t$, where $t$ denotes the current time and $\Delta t$ the time step, with Eqs. (6) - (9), it is obtained a linear multistep form of the Bathe method:

$$
\left(72 \mathbf{M}+8 c_{0}^{2} \Delta t^{2} \mathbf{K}\right)^{t+\Delta t} \mathbf{U}+\left(-144 \mathbf{M}+5 c_{0}^{2} \Delta t^{2} \mathbf{K}\right)^{t+\frac{\Delta t}{2}} \mathbf{U}+\left(72 \mathbf{M}+5 c_{0}^{2} \Delta t^{k} \mathbf{K}\right)^{t} \mathbf{U}=\mathbf{0}
$$

Using the definition of the $C F L$ number, $C F L=\frac{c_{0} \Delta t}{h}$, where $h$ is the "characteristic length" of a finite element (or fundamental length used), Eq. (10) becomes:

$$
(72 \mathbf{M}+8 \gamma K)^{t+\Delta t} \mathbf{U}+(-144 \mathbf{M}+5 \gamma \mathbf{K})^{t+\frac{\Delta t}{2}} \mathbf{U}+(72 \mathbf{M}+5 \gamma \mathbf{K})^{t} \mathbf{U}=\mathbf{0}
$$

where $\gamma=C F L^{2} h^{2}[5]$.

\section{Results}

Figures 5 to 7 represent the outputs of the numerical simulations for the horizontal stress, vertical stress and the vertical displacement in the layers of the road pavement. Results have 
been obtained in axisymmetric 2D simulations in $\mathrm{XZ}$ plane. Overall, the results show minor differences between values of the stresses and the displacement for the pavements with different composition and thickness of the layers.

\subsection{Concrete pavement}

The results of the stress-strain analysis from the numerical simulation are plotted in Fig. 5. The horizontal stress reached the maximum value $720 \mathrm{kPa}$, which is located at the interface of the cement-concrete layer and cement bound granular mixture layer. The maximum value of the vertical stress is $133 \mathrm{kPa}$ and is located in the first cement-concrete layer. The maximum vertical displacement in Z-direction reached $0.14 \mathrm{~mm}$.

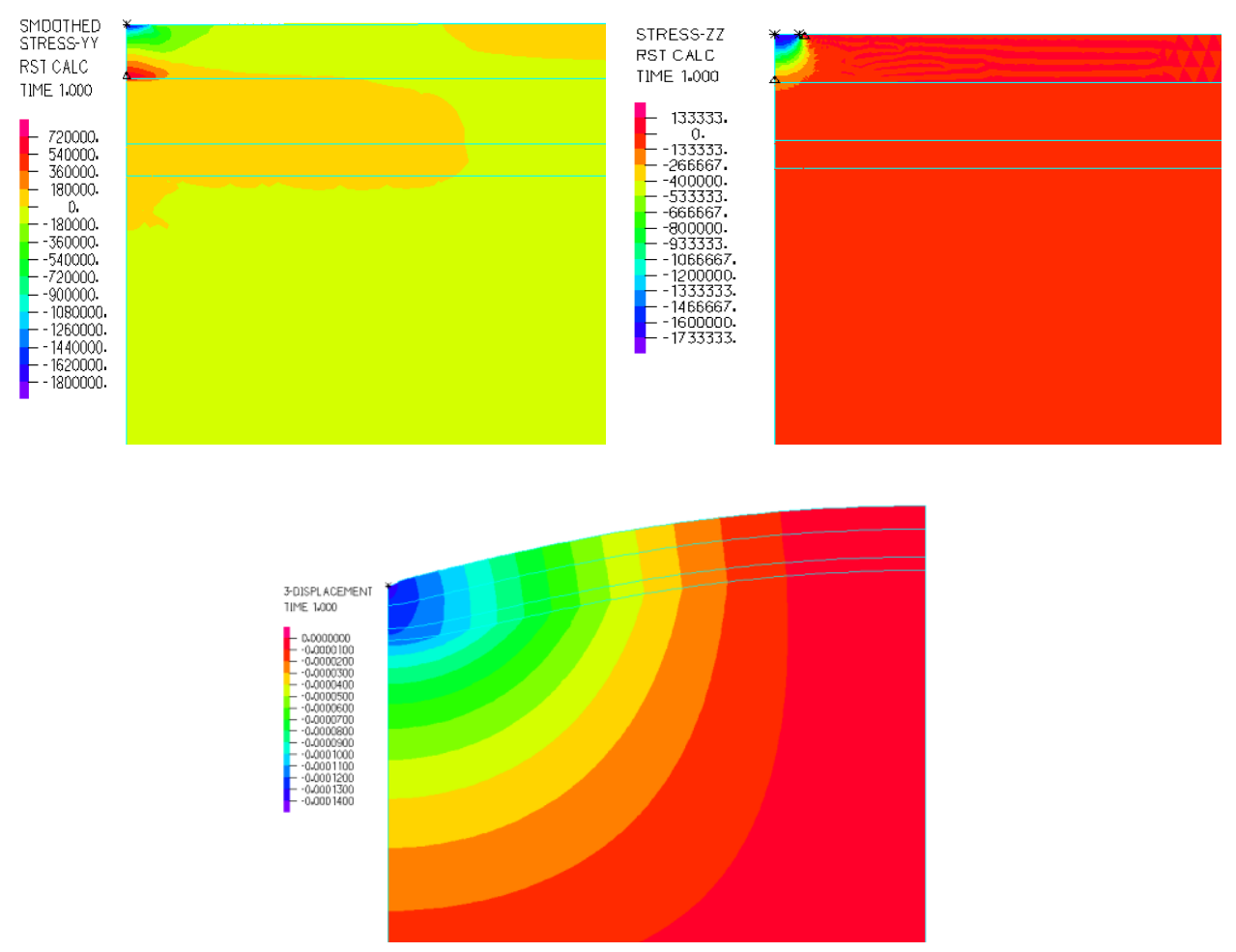

Fig. 5. Results of the stress-strain analysis for the concrete pavement.

\subsection{Semi-rigid pavement}

The results of the stress-strain analysis from the numerical simulation are plotted in Fig. 6. The horizontal stress reached the maximum value $675 \mathrm{kPa}$, which is located at the interface of graded aggregate layer and the subgrade. The maximum value of the vertical stress is $133 \mathrm{kPa}$ and is located in the first stone mastix asphalt layer. The maximum vertical displacement in Z-direction reached $0.42 \mathrm{~mm}$. 

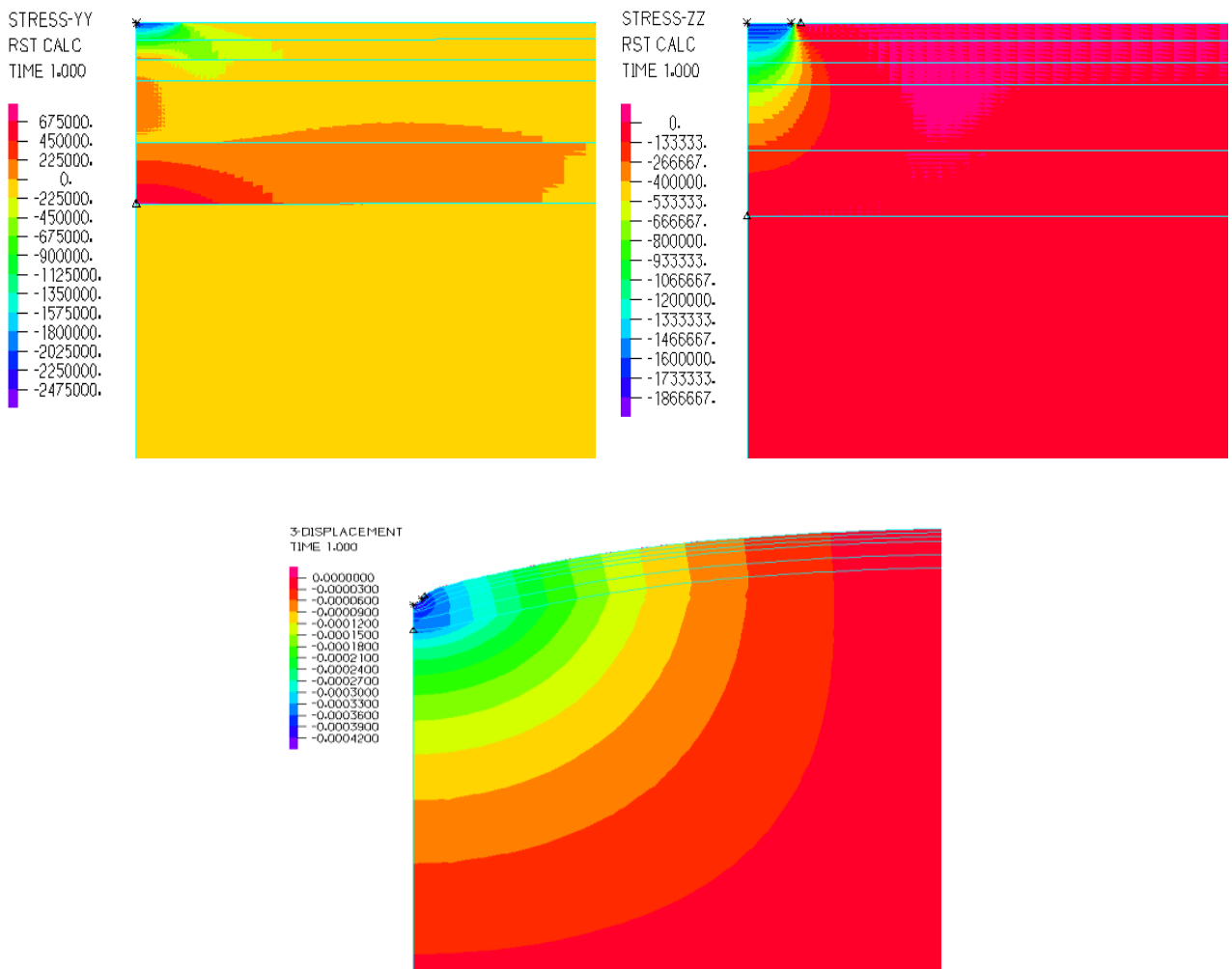

Fig. 6. Results of the stress-strain analysis for the semi-rigid pavement.

\subsection{Flexible pavement}

The results of the stress-strain analysis from the numerical simulation are plotted in Fig. 7. The horizontal stress reached the maximum value $675 \mathrm{kPa}$, which is located at the interface of the asphalt concrete layer and the unbound mixture layer. The maximum value of the vertical stress is $150 \mathrm{kPa}$ and is located in first stone mastix asphalt layer. The maximum vertical displacement in Z-direction reached $0.315 \mathrm{~mm}$.
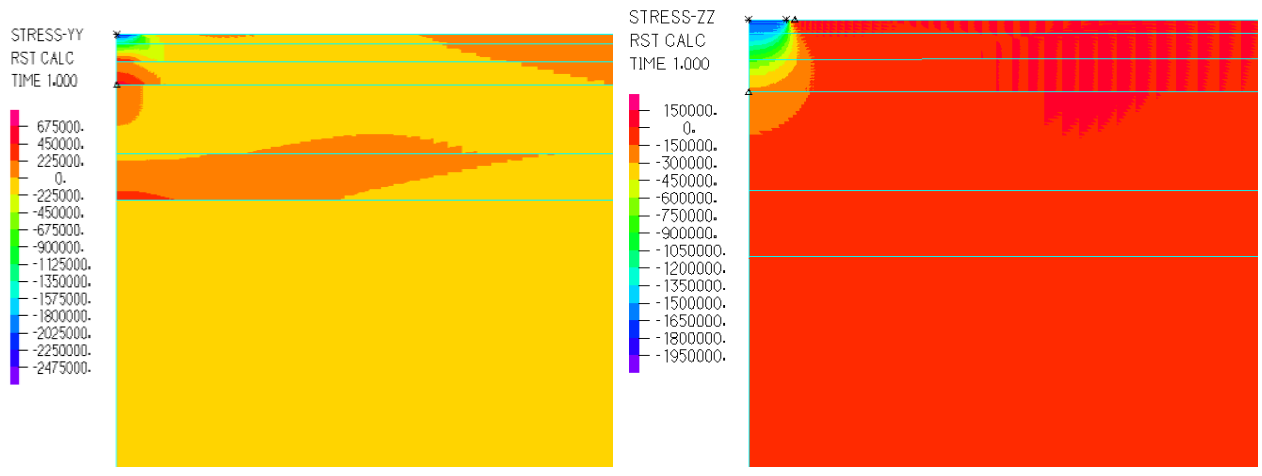


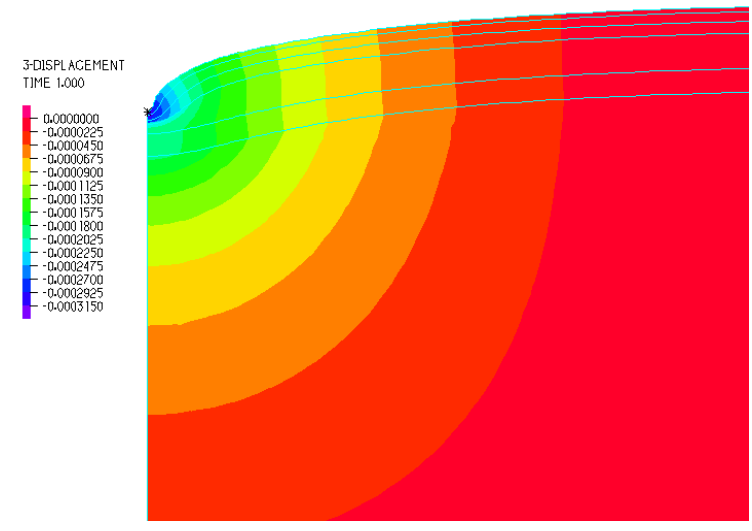

Fig. 7. Results of the stress-strain analysis for the flexible pavement.

\section{Conclusion}

The presented results show that the utilization of the FEM methods can be useful for solving the phenomenon of the vehicle-ground interaction. The stress-strain analysis show minor differences in the stress distribution in the pavement structure for the selected pavement types in terms of the maximum reached values but vertical displacements differ for asphalt concrete and cement concrete pavements. This variance is caused by the higher stiffness of the cement concrete slab of the concrete pavement. Further investigation will involve fully three dimensional analyses of the stress-strain state of the ground under dynamic effects of the moving load.

This paper was supported by the Grant National Agency VEGA of the Slovak Republic (Grant No. $1 / 0005 / 16)$.

\section{References}

[1] L. Fryba, Vibration of Solids and Structures under Moving Loads (ACADEMIA, Praha, Nordhoff International Publishing, Groningen, 1972)

[2] I. Martinicka, Pozemné komunikácie a dráhy, 6, 41-50 (2010)

[3] L. Daniel, V. Valašková, J. Kortiš, Civil and Environmental Engineering, 10, 108-112 (2014)

[4] ADINA R \& D. Theory and Modeling Guide. Volume I (ADINA. ADINA R \& D, Inc., Watertown, MA, USA, 2012)

[5] N. Gunwoo, H. Seounghyun, K. J. Bathe, Comput. Struct. 123, 93-105 (2013) 